\title{
HIV and liver transplantation: The British Columbia experience, 2004 to 2013
}

\author{
Clara Tan-Tam MD PhD FRCSC ${ }^{1}$, Pamela Liao MD², Julio S Montaner MD DSc FRCPC 3,4 , \\ Mark W Hull MD FRCPC ${ }^{3,4}$, Charles H Scudamore MD MSC FRCSC ${ }^{1,5}$, \\ Siegfried R Erb MD FRCPC 5,6 , Eric M Yoshida MD MHSC FRCPC 5,6
}

\begin{abstract}
C Tan-Tam, P Liao, JS Montaner, et al. HIV and liver transplantation: The British Columbia experience, 2004 to 2013. Can J Infect Dis Med Microbiol 2014;25(3):159-162.
\end{abstract}

BACKGROUND: The demand for definitive management of endstage organ disease in HIV-infected Canadians is growing. Until recently, despite international evidence of good clinical outcomes, HIV-infected Canadians with end-stage liver disease were ineligible for transplantation, except in British Columbia (BC), where the liver transplant program of $\mathrm{BC}$ Transplant has accepted these patients for referral, assessment, listing and provision of liver allograft. There is a need to evaluate the experience in $\mathrm{BC}$ to determine the issues surrounding liver transplantation in HIV-infected patients.

METHODS: The present study was a chart review of 28 HIV-infected patients who were referred to BC Transplant for liver transplantation between 2004 and 2013. Data regarding HIV and liver disease status, initial transplant assessment and clinical outcomes were collected.

RESULTS: Most patients were $\mathrm{BC}$ residents and were assessed by the multidisciplinary team at the $\mathrm{BC}$ clinic. The majority had undetectable HIV viral loads, were receiving antiretroviral treatments and were infected with hepatitis $C$ virus $(n=16)$. The most common comorbidities were anxiety and mood disorders $(n=4)$, and hemophilia $(n=4)$. Of the patients eligible for transplantation, four were transplanted for autoimmune hepatitis ( 5.67 years post-transplant), nonalcoholic steatohepatitis (2.33 years), hepatitis $\mathrm{C}$ virus ( 2.25 years) and hepatitis B-delta virus coinfection (recent transplant). One patient died from acute renal failure while waiting for transplantation. Ten patients died during preassessment and 10 were unsuitable transplant candidates. The most common reason for unsuitability was stable disease not requiring transplantation $(n=4)$.

CONCLUSIONS: To date, interdisciplinary care and careful selection of patients have resulted in successful outcomes including the longest living HIV-infected post-liver transplant recipient in Canada.

Key Words: Hepatitis; HIV; Liver; Transplant

\section{Le VIH et la transplantation hépatique : l'expérience britanno-colombienne de 2004 à 2013}

HISTORIQUE : La demande d'une prise en charge définitive des maladies organiques terminales chez les Canadiens infectés par le VIH est en hausse. Jusqu'à tout récemment, malgré des données internationales faisant foi de résultats cliniques positifs, les Canadiens atteints d'une maladie hépatique terminale infectés par le VIH n'étaient pas admissibles à une transplantation, sauf en Colombie-Britannique (C.-B.), où le programme de transplantations de BC Transplant les accepte en vue d'un aiguillage, d'une évaluation, de l'inscription sur la liste d'attente et de l'exécution d'une allogreffe du foie. L'évaluation de l'expérience de la C.-B. s'impose pour déterminer les enjeux entourant la transplantation hépatique chez les patients infectés par le VIH.

MÉTHODOLOGIE : Les chercheurs ont procédé à l'étude des dossiers des 28 patients infectés par le VIH qui ont été orientés vers BC Transplant pour subir une transplantation hépatique entre 2004 et 2013. Ils ont colligé les données sur l'état du VIH et de la maladie hépatique, l'évaluation initiale de la transplantation et les résultats cliniques.

RÉSULTATS : La plupart des patients étaient des habitants de la C.-B. qui avaient été évalués par l'équipe multidisciplinaire de la clinique de C.-B. La majorité présentait des charges virales indétectables du VIH, prenaient des antirétroviraux et étaient infectés par le virus de l'hépatite $\mathrm{C}(\mathrm{n}=16)$. Les comorbidités les plus courantes étaient l'anxiété et les troubles des humeurs $(n=4)$, ainsi que l'hémophilie $(n=4)$. Parmi les patients admissibles à la transplantation, quatre ont subi une transplantation consécutive à une hépatite auto-immune (5,67 ans après la transplantation), à une stéatose hépatique non alcoolique (2,33 ans), à un virus de l'hépatite $\mathrm{C}$ (2,25 ans) et à une co-infection par l'hépatite $\mathrm{B}$ et le virus delta (transplantation récente). Un patient est décédé d'une insuffisance rénale aiguë alors qu'il était en attente de transplantation. Dix sont décédés pendant la préévaluation et dix n'étaient pas des candidats adéquats pour la transplantation. La principale raison de ne pas être un candidat adéquat était une maladie stable ne nécessitant pas de transplantation $(n=4)$.

CONCLUSIONS : Jusqu'à présent, les soins interdisciplinaires et une sélection attentive des patients permettent d'obtenir des résultats positifs, y compris la présence au Canada du greffé hépatique infecté par le VIH ayant vécu le plus longtemps depuis sa transplantation.

has been demonstrated that similar levels of immunosuppression are required for both HIV-infected and HIV-noninfected recipients to prevent graft rejection $(2,3)$. In addition, the rates of surgical complications are similar to what has been observed in the non-HIV setting in carefully selected HIV-infected liver and kidney transplant recipients (4).

Nevertheless, the management of HIV-infected transplant recipients is complex because there are numerous pharmacokinetic interactions between certain antiretroviral agents and immunosuppressants
The life expectancy of an individual infected with HIV in the modern antiretroviral therapy (ART) era is approaching parity with the general population in North America, and HIV is becoming increasingly recognized as a chronic illness in developed countries. Concerns surrounding opportunistic infections due to immunocompromise and reduced survival have been attenuated (1).

It was once believed that further immunosuppression of HIV-positive patients would further exacerbate opportunistic infection. However, it
${ }^{1}$ Department of Surgery; ${ }^{2}$ Obstetrics and Gynecology, University of Toronto, Toronto, Ontario; ${ }^{3}$ Division of AIDS; ${ }^{4}$ Division of Gastroenterology,
University of British Columbia; ${ }^{5} \mathrm{BC}$ Centre for Excellence in HIVIAIDS; ${ }^{6}$ Liver Transplant Program, Vancouver General Hospital,

Vancouver, British Columbia

Correspondence: Dr Eric M Yoshida, Division of Gastroenterology, Vancouver General Hospital, Diamond Health Care Centre, 5th Floor, 2775 Laurel Street, Vancouver, British Columbia V5Z 1M9. Telephone 604-875-5371, fax 604-875-5447, e-mail eric.yoshida@vch.ca
OPEN $\bigcirc$ ACCESS

This open-access article is distributed under the terms of the Creative Commons Attribution Non-Commercial License (CC BY-NC) (http:// creativecommons.org/licenses/by-nc/4.0/), which permits reuse, distribution and reproduction of the article, provided that the original work is properly cited and the reuse is restricted to noncommercial purposes. For commercial reuse, contact support@pulsus.com 


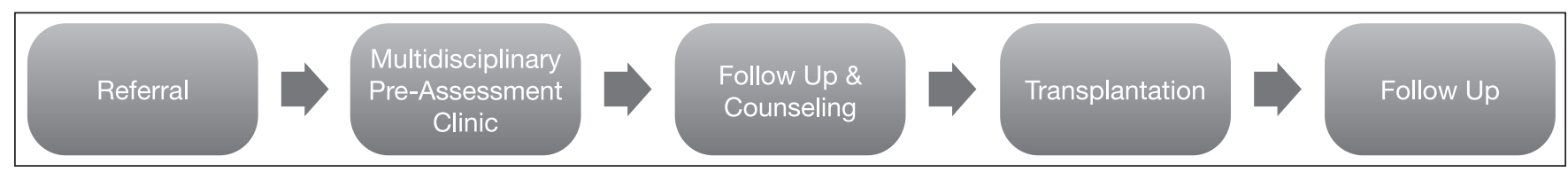

Figure 1) Steps of patient care

\section{TABLE 1}

Demographic information for referred patients

\begin{tabular}{lcc}
\hline & Male & Female \\
\hline Referrals $(\mathrm{n}=28), \mathrm{n}(\%)$ & $23(82)$ & $5(18)$ \\
Assessed in clinic $(\mathrm{n}=23), \mathrm{n}(\%)$ & $17(74)$ & $4(17)$ \\
Age, years, mean & 47 & 43 \\
Follow-up, months, mean & \multicolumn{2}{c}{4.1} \\
\hline
\end{tabular}

$(5,6)$. Specifically, tacrolimus tends to demonstrate a longer half-life and more unpredictable levels (6). Despite these additional complexities, multiple studies have demonstrated that graft and patient survivorship are comparable between HIV-infected and noninfected groups (3). HIV infection is, thus, no longer considered to be a contraindication to liver transplantation (1).

The prevelance of end-stage liver disease (ESLD) as the result of hepatitis $\mathrm{C}$ virus (HCV) and hepatitis $\mathrm{B}$ virus (HBV) coinfection is $23 \%$ to $33 \%$ and $9 \%$, respectively (7). HIV coinfection accelerates the progression of ESLD, in addition to a decrease in patient and graft survival rate. This continues to pose a challenge to health care teams. Despite decreased survival and increased complication rates in HIVHCV coinfected recipients (8), these individuals are still considered for transplantation and retransplantation if required. Because they experience accelerated disease progression, standard evaluation processes are not completely applicable to evaluation of these patients because it does not reflect nor predict the natural history of their disease (8).

There are many factors involved in selecting transplant recipient candidates and in the management of HIV-positive recipients. These include the patient's infection status, the severity of their liver disease, the scarcity of resources, and the management of immunosuppression and viral infection.

In general, at our institution, patients selected as transplant candidates are assessed and discussed at multidisciplinary board meetings. Medical urgency is the primary criterion for determining patient eligibility for transplant. Previously, HIV seropositivity was an absolute exclusion for transplantation. The transplant program in British Columbia (BC) has recognized that HCV-HIV coinfected patients experience accelerated disease and liver transplantation has been offered to HIV-infected patients in BC since 2004. The BC Transplant Society has subsequently adopted a policy, developed by the transplant team, regarding standard assessment criteria for HIV-infected patients being considered for transplantation (Figure 1).

Given the limited data regarding assessment and outcomes of HIV. infected patients referred for liver transplantation in the Canadian setting, we undertook a review of the first $28 \mathrm{HIV}$-infected patients in the BC Liver Transplant Program.

\section{METHODS}

The present study was a retrospective chart review of $28 \mathrm{HIV}$-infected candidates between 2004 and 2013. These candidates were all referred to the BC Transplant Program for liver transplantation. All patients were seen by both the transplant social worker and the transplant psychologist, in addition to the transplant hepatology and surgical staff, and the transplant coordinators. The authors can only report what the transplant candidates disclosed to the assessment team. Although it may appear that the candidates misled the assessment team in certain respects, there is no proof of this and, therefore, from an ethical perspective, the patients' disclosures were assumed to be truthful.

The data were collected from medical records and kept confidential. There were no specific identifying patient data used in the case discussion.
The reasons for referral for transplantation were reviewed, in addition to the status of the patients and their clinical outcomes. The present study was approved by the University of British Columbia Clinical Research Ethics Board (Vancouver, BC).

The Liver Transplant Program's policy with regard to placement of HIV-infected patients on the transplant waiting list after successful assessment include the following:

1. All candidates must meet the general criteria for transplantation that applies to all non-HIV-infected candidates (eg, no active infection, no active malignancy, abstinence from substance abuse, etc).

2. Candidates should be on ART supervised by an HIV specialist.

3. Candidates must be free from opportunistic infection.

4 The HIV viral load should be undetectable.

5. Although there is no absolute threshold CD4 count, the minimum accepted CD4 count is approximately 150 cells $/ \mathrm{mm}^{3}$

Patients who did not meet these criteria were assessed on an individual basis.

\section{RESULTS}

\section{Demographics}

Since 2004, there have been 28 HIV-infected patients referred for liver transplant assessment. The majority (23 of 28 [82\%]) of these patients were men and most were assessed as outpatients of the preassessment clinic, with a small minority referred to the transplant program as inpatients (including hospital to hospital transfer for assessment). The mean age of these patients was 47 years and the mean follow-up time was 4.1 months (Table 1 ). The majority of these patients were $\mathrm{BC}$ residents; some were from other provinces and one was from the United States.

All patients had chronic liver disease and there were no patients with acute liver failure assessed. One patient in an out-of-province hospital was referred on an urgent basis to the Liver Transplant Program with acute drug hepatotoxicity secondary to highly active ART (HAART) medications. The Program accepted the patient in transfer for the purposes of expedited transplant assessment but the patient died en route to $\mathrm{BC}$. There have been no other referrals of HIV-infected patients with acute liver failure. The majority of assessed patients were coinfected with HCV. Five patients were coinfected with HBV and seven patients had nonviral causes of liver failure. Of the non-liver and non-HIV-related medical comorbidities, the majority of these patients also had hemophilia, anxiety and depression (Table 2).

Five patients were activated for transplantation and four were tranplanted. One patient had autoimmune hepatitis, one had nonalcoholic hepatosteatosis, one had hepatitis $\mathrm{C}$, one had HBV and hepatitis delta virus coinfection, and one died waiting (Table 3). One listed patient died from acute renal failure before transplantation. This patient was from out of province and referred to our centre specifically because of HIV infection. The most common reason for transplant unsuitablility was stable liver disease not requiring transplantation $(n=4)$. The patients had undetectable HIV viral loads and were on HAART at the time of transplantation. Currently, three patients with HCV are being assessed to determine whether they are suitable transplant candidates.

\section{Description of transplant recipients}

Patient 1 was transplanted at 59 years of age for autoimmune hepatitis. This patient is now six years, four months post-transplant. This patient's HIV infection is well controlled on abacavir, lamivudine and nelfenavir. His immunosuppression induction consisted of low-dose 
TABLE 2

Background profiles of all patients referred to clinic $(n=28)$

\begin{tabular}{ll}
\hline Liver disease and etiology & $\begin{array}{l}\text { Non-HIV or liver-related medical } \\
\text { comorbidities }\end{array}$ \\
\hline Chronic hepatitis $B(n=5)$ & Anxiety/depression $(n=4)$ \\
Chronic hepatitis C $(n=16)$ & Hemophilia $(n=4)$ \\
Other causes $(n=7)$ & Hypertension $(n=2)$ \\
Cirrhosis secondary to ART & Epilepsy $(n=2)$ \\
Autoimmune & Gout $(n=2)$ \\
Chronic active hepatitis & Endocarditis $(n=2)$ \\
Cryptogenic cirrhosis & Benign prostatic hypertrophy $(n=2)$ \\
Alcoholic cirrhosis & \\
Liver failure NYD & \\
Nonalcoholic steatohepatitis & \\
Sclerosing cholangitis & \\
\hline ART Antiretroviral therapy:
\end{tabular}

ART Antiretroviral therapy; NYD Not yet diagnosed

tacrolimus (ie, $0.5 \mathrm{mg}$ every third day), mycophenolate mofetil and tapered corticosteroids because pharmacokinetic interactions with the HAART medications occurred. This patient sustained acute renal injury while on tacrolimus; however, renal function has recovered and his graft is now receiving mycophenolate mofetil monotherapy. This patient has not experienced any rejection episodes; however, he has required regular endoscopic retrograde cholangiopancreatography to manage and drain biliary sludge due to recurrent biliary anastomotic stricture. As a result, he has a persistent increase in hepatobiliary liver biochemistry (ie, alkaline phosphatase, gammaglutamyl transferase). A recent liver biopsy was unremarkable (Table 3).

Patient 2 was transplanted at 55 years of age for nonalcoholic steatohepatitis (NASH). This patient is three years post-transplant. This patient's HIV is controlled with abacavir/lamivudine (Kivexa, ViiV Healthcare, Canada) and raltegravir, and because there were no drug interactions, the standard induction tacrolimus, mycophenolate mofetil and tapered corticosteroid dosing was used. This patient also has not experienced any graft rejection, but developed persistent increases in his serum alanine aminotransferase (ALT) level, which was previously normal (ie, ALT $120 \mathrm{U} / \mathrm{L}$ to $150 \mathrm{U} / \mathrm{L}$ ). This was initially attributed to recurrent NASH at one year, four months posttransplant. He was subsequently discovered to have acquired acute HCV genotype $1 \mathrm{~b}$ infection that is now chronic. Recent elastography (Fibroscan, Echosens, France) revealed only mild fibrosis (ie, Metavir score F1, where F4 is cirrhosis).

Patient 3 was transplanted at 49 years of age for HCV coinfection and is two years, six months post-transplant. This patient's HIV infection is controlled with Kivexa and raltegravir, and also received standard induction dosing with tacrolimus, mycophenolate mofetil and tapered corticosteroids. At three months post-transplant, it was demonstrated biochemically and with a liver biopsy that there was evidence of graft hepatitis and Metavir stage 2 fibrosis (ie, F2). Two years later, this patient has experienced decreasing ALT and aspartate aminotransferase (AST) levels, with an increased serum bilitrubin level but no other evidence of decompensation. At two years, three months post-transplant, the patient suddenly developed ascites indicative of cirrhotic decompensation. The patient's ascites is being managed with diuretics with the hope that he will be suitable for a non-interferon-based antiviral regimen in the future (Table 3).

The final transplanted patient is 50 years of age and has HBV and hepatitis delta virus coinfection, and hepatocellular carcinoma. This patient is nine months post-transplant. The immediate post-transplant complications included postoperative bleeding, acute renal dysfunction and delayed surgical biliary anastomosis. Pretransplant, the patient's HIV antiviral agents included tenofovir DF/emtricitabine and raltegravir. His HBV viral load was undetectable and locoregional therapy of his hepatocellular carcinoma included transarterial chemoembolization. Post-transplant, he has received hepatitis
TABLE 3

Outcomes of patients referred and assessed in clinic $(n=23)$

\begin{tabular}{ll}
\hline Outcome & $\mathbf{n}$ \\
\hline Deemed unsuitable & 8 \\
Patient recovered & 1 \\
Medical reasons & 1 \\
Lack of symptoms & 1 \\
Insufficient CD4 count & 3 \\
Lost to follow-up & 2 \\
Died in preassessment stage & 10 \\
Liver failure & 5 \\
Multisystem organ failure & 2 \\
Pneumonia & 1 \\
Infection & 1 \\
Unknown cause & 1 \\
Declined transplant & 1 \\
Activated for transplant & 5 \\
Transplanted & 1 \\
Autoimmune hepatitis & 4 \\
Nonalcoholic hepatoseatosis & 1 \\
Hepatitis C & 1 \\
Hepatitis B and D, and hepatocellular carcinoma & 1 \\
Died waiting & 1 \\
\hline No graft loss or patient death to date (follow-up & 1 \\
\hline
\end{tabular}

${ }^{*}$ No graft loss or patient death to date (follow-up $=8$ months to $>4$ years)

immunoglobulin in addition to tenofovir. Despite a prolonged hospitalization for convalescence and physical rehabilitation, the patient is stable as an outpatient. His hepatitis B surface antigen and hepatitis D nuclei acid tests have remained negative (Table 3).

Overall, the post-transplant quality of life in these transplant recipients has been excellent, although the recipient with pretransplant HCV infection has developed ascites more than two years post-transplant.

\section{DISCUSSION}

Nearly a decade after the establishment of an HIV liver transplant program in BC, we demonstrated that successful transplantation in HIVinfected and HIV-HCV coinfected patients is possible. The success of these candidates is due to a multidisciplinary team that includes a transplant surgical team, transplant medicine team, HIV specialty team and psychosocial support. These patients were selected for transplantation based on their failing liver disease. There is absolutely no bias against the HIV-infected individual; in fact, we have been their advocates. In the first year of the program, and in the time leading up to the establishment of the program, there was uncertainty as to what subgroup of HIV-infected patients would be suitable for transplantation. Within a short time, however, the attitude of the liver transplant program became one of advocacy. With the realization that patients outside of BC did not have any option for transplantation within Canada, it was decided that no referred patient with HIV would be declined without assessment, both inside $\mathrm{BC}$ and outside of the province.

Information about death during preassessment is often not accurate because if a patient dies during the preassessment, the liver transplant program is not informed immediately by the community physicians and hospitals. In general, death during the assessment is often a reflection of an untimely late referral because the patient should have been referred earlier, or is a reflection of a patient's nonadherence to clinic appointments; however, it is not the aim of the present article to criticize the referring physician or the patient.

We note that our three long-term transplant recipients are the longest-surviving HIV-infected transplant recipients in Canada and were the second, third and fourth HIV-infected patients to receive liver transplants in this country. To date, three HIV-monoinfected recipients have experienced rejection-free survival. The HIV-HCV coinfected patient has experienced graft hepatitis from $\mathrm{HCV}$ 
recurrence but has not yet developed graft loss. This patient may be a candidate for non-pegylated interferon-based direct antiviral therapy in the future. Better control of HCV replication would improve graft survival in the future. The patient who acquired HCV post-transplant remains stable and, if advanced fibrosis develops, he would be considered a candidate for antiviral therapy. These patients also did not experience more intraoperative nor postoperative surgical complications compared with their non-HIV-infected recipients.

Our experience, as well as the experience of others, confirms that the post-transplant management of HIV-infected recipients is complex. Not only is management of coinfected patients necessary, one must also address the management and appropriate dosing of HAART medications. Immunosuppressive medications, specifically the calcineurin inhibitors, tacrolimus and cyclosporine, must be dose reduced and drug trough levels followed extremely carefully because pharmacokinetic interactions may lead to toxic levels. Our first patient was on nelfinavir and required a single, small dose of tacrolimus every third day, whereas the usual dose is twice daily at higher doses. Nelfinavir is metabolized by cytochrome P450 3A4, which also metabolizes tacrolimus and is well known to cause significant interactions; therefore, the dose of tacrolimus must be reduced by a factor of 70 compared with normal in the setting of nelfinavir therapy (10). Eventually, our first patient was able to have tacrolimus discontinued, with maintenance immunosuppression consisting of mycophenolate mofetil monotherapy, and remains free from acute graft rejection. The other ART medications used in our transplant recipients were abacavir/lamivudine, raltegravir and emtricitabine/tenofovir. None of these drugs are reported to have significant interactions with tacrolimus (11-13) and we have not encountered any. Drug-drug interactions with ART medications and immunosuppressive therapy may appear challenging a priori, but are easily overcome, and the special management issues regarding HIV and liver transplantation become routine thereafter. We consider the multidisciplinary post-transplant approach to these patients involving allied health care professionals, including post-transplant clinic nurses and transplant pharmacists, essential to the immunosuppressive management of these patients. Currently, the management of HIV-HCV coinfection remains challenging and it is acknowledged that overall, decreased post-transplant survival is observed (7). Nonetheless, it is clearly a subgroup within the cohort of post-transplant HIV-HCV infected patients who can achieve a substantial survival benefit (7). For patients with decompensated allograft cirrhosis, there is the potential of possible HCV viral clearance with noninterferon-based protocols, although more post-transplant clinical trials will need to be conducted to determine whether this is feasible.

\section{REFERENCES}

1. Chin-Hong P, Beatty G, Stock P. Perspectives on liver and kidney transplantation in the human immunodeficiency virus-infected patient. Infect Dis Clin North Am 2013;27:459-71.

2. Frassetto LA, Tan-Tam C, Stock PG. Renal transplantation in patients with HIV. Nat Rev Nephrol 2009;5:582-9.

3. Tan-Tam C, Frassetto LA, Stock PG. Liver and kidney transplantation in HIV-infected patients. AIDS Rev 2009;11:190-204.

4. Harbell J, Fung J, Nissen N, et al. Surgical complications in 275 HIVinfected liver and/or kidney transplantation recipients. Surgery 2012;152:376-81.

5. Wilby KJ, Greanya ED, Ford JA, Yoshida EM, Partovi N. A review of drug interactions with boceprevir and telaprevir: Implications for HIV and transplant patients. Ann Hepatol 2013;11:179-85.

6. Frassetto LA, Tan-Tam C, Barin B, et al. The best single time point measurement correlations with AUC for cyclosporine and tacrolimus in HIV-infected kidney and liver transplant recipients. Transplantation 2013 (In press).

7. Fung J, Eghtesad B, Patel-Tom K, DeVera M, Chapman H, Ragni M. Liver transplantation in patients with HIV infection. Liver Transpl 2004;10:S39-S53.

8. Terrault NA, Roland ME, Schiano T, et al. Outcomes of liver transplant recipients with hepatitis $\mathrm{C}$ and human inmmunodeficiency virus coinfection. Liver Transpl 2012;18:716-26.
Therefore, we do not see any reason to restrict the liver transplant process to only HIV-infected individuals without HCV coinfection. We note that our HIV-HBC-HCV tri-infected patient is very stable nine months post-transplant with appropriate anti-HBV prophylaxis. It should be noted that before 1996, HBV was a contraindication in Canada for transplant; currently, however, $\mathrm{HBV}$ is considered to be a prime indication for transplantation.

In the time period leading up to the decision to offer liver transplantation to HIV-infected patients, there was a great deal of concern, both within and outside of the transplant program, of the risk to operating room personnel from viral transmission of HIV during an occupational injury such as a needlestick accident. Viral transmission during surgery poses a major concern among health care providers. The risk for transmission of $\mathrm{HIV}$ is $0.3 \%$ (95\% CI $0.2 \%$ to $0.5 \%$ ) and is lower than the risk for transmission of $\mathrm{HCV}(1.8 \%$; range $0 \%$ to $7 \%)$ $(14,15)$. In the setting of HIV, as in all health care practices, universal precautions should be practiced routinely; after the first liver transplant surgery was performed using standard precautions, the concerns regarding intraoperative viral transmission dissipated as the very minimal threat of inadvertent viral transmission became apparent.

\section{CONCLUSION}

The life-span of an HIV-infected individual receiving HAART is now near that of their noninfected counterparts (15). HIV is recognized as a chronic disease controlled with HAART (16). The demand for liver transplantion as definitive management for ESLD will only increase. Despite increasing public awareness, developing living-related-donor programs and exploring other potential donors, there continues to be an organ shortage. Until better treatments for ESLD are developed and implemented, both in the HIV patient population and the non-HIV patient population, the demand for liver transplant for definitive management of ESLD will only increase. Although our single-centre experience in Canada is noteworthy, we acknowledge that any single-centre experience is limited and we are hopeful that a Canadian national database will be established as transplantation of HIV-infected patients becomes more common.

ACKNOWLEDGEMENTS: The authors acknowledge the dedication of their pretransplant coordinators, their post-transplant and transplant ward clinic nurses, their transplant pharmacists, transplant psychologists and social workers. They also thank the operating room staff and staff of the Intensive Care Unit of the Vancouver General Hospital, BC Transplant (an agency of the Provincial Health Services Authority), the HIV Centre for Excellence and the Oak Tree Clinic of Vancouver.

9. Subramanian A, Sulkowski M, Barin B, et al. MELD score is an important predictor of pretransplantaion mortality in HIV-infected liver transplant candidates. Gastroenterology 2010;138:159-64.

10. Schvarcz R, Rudbeck G, Soderdahl G, Stahle L. Interaction between nelfinavir and tacrolimus after orthotopic liver transplantation in a patient co-infected with HIV and hepatitis C (HCV). Transplantation 2000;69:2194-5.

11. Sivasubramanian G, Frempong-Manso E, MacArthur RD. Abacavir/lamivudine combination in the treatment of HIV: A review. Ther Clin Risk Manag 2010;6:83-94.

12. Tricot L, Teicher E, Peytavin G, et al. Safety and efficacy of raltegravir in HIV-infected transplant patients co-treated with immunosuppressive drugs. Am J Transpl 2009;9:1946-52.

13. Chittick GE, Zong J, Begley JA, et al. Pharmacokinetics of emtricitabinetenofovir disoproxil fumerate and tacroliums at steady state when administered in combination. Int J Clin Pharmacol Ther 2008;46:627-36.

14. Yoshida EM. HIV, liver transplantation, and scarce lifesaving resources. BCMJ 2004;46:16-7.

15. Mullen MA, Kohut N, Sam M, Blendis L, Singer PA. Access to adult liver transplantation in Canada: A survey and ethical analysis. CMAJ 1996;154:337-42.

16. Manfredi R. HIV infection and advanced age emerging epidemiological, clinical and management issues. Ageing Res Rev 2004;3:31-54. 


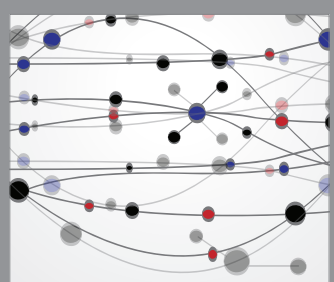

The Scientific World Journal
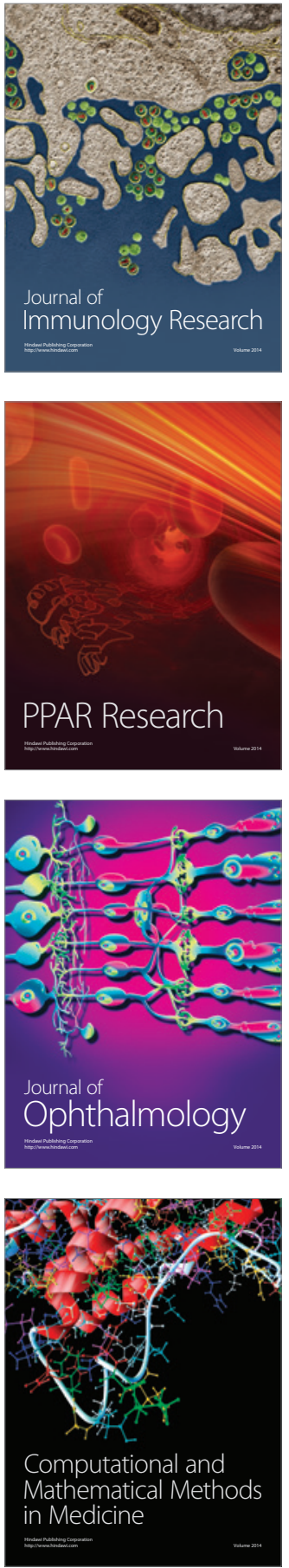

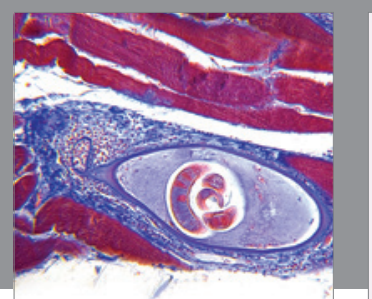

Gastroenterology Research and Practice

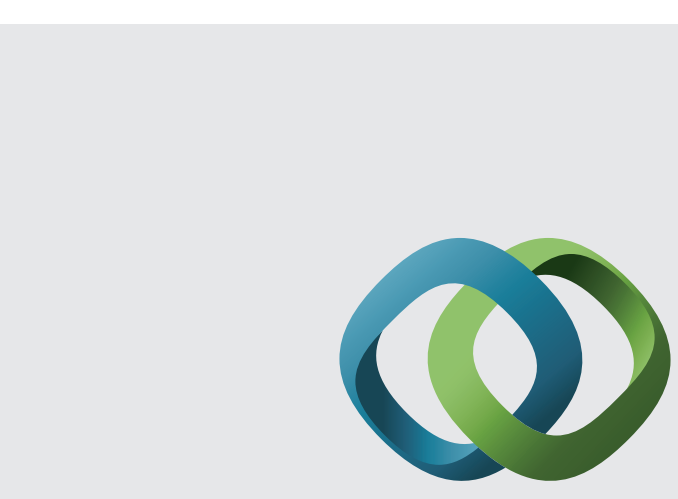

\section{Hindawi}

Submit your manuscripts at

http://www.hindawi.com
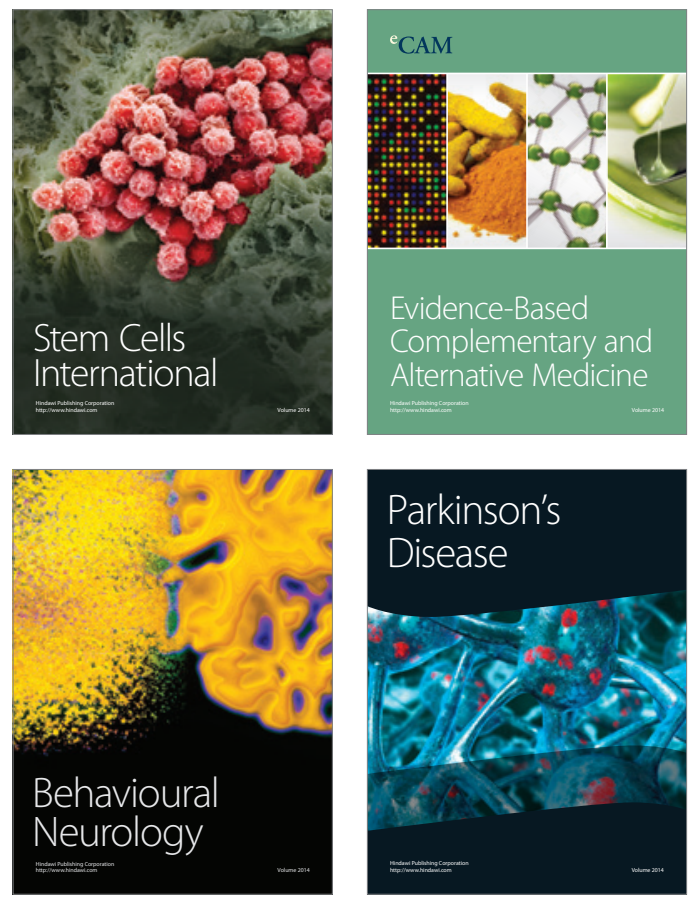
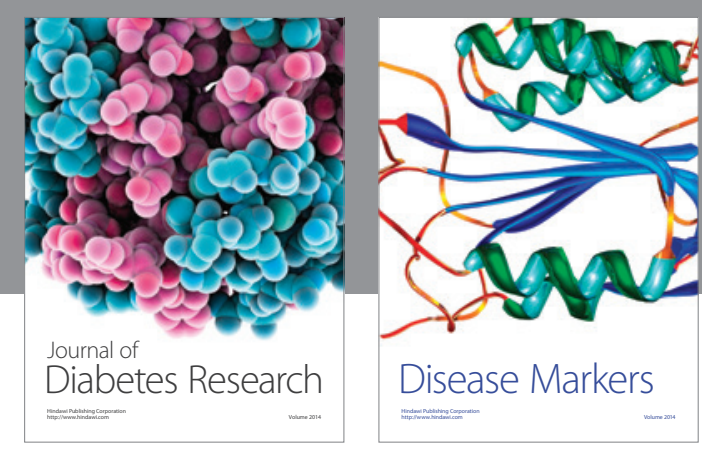

Disease Markers
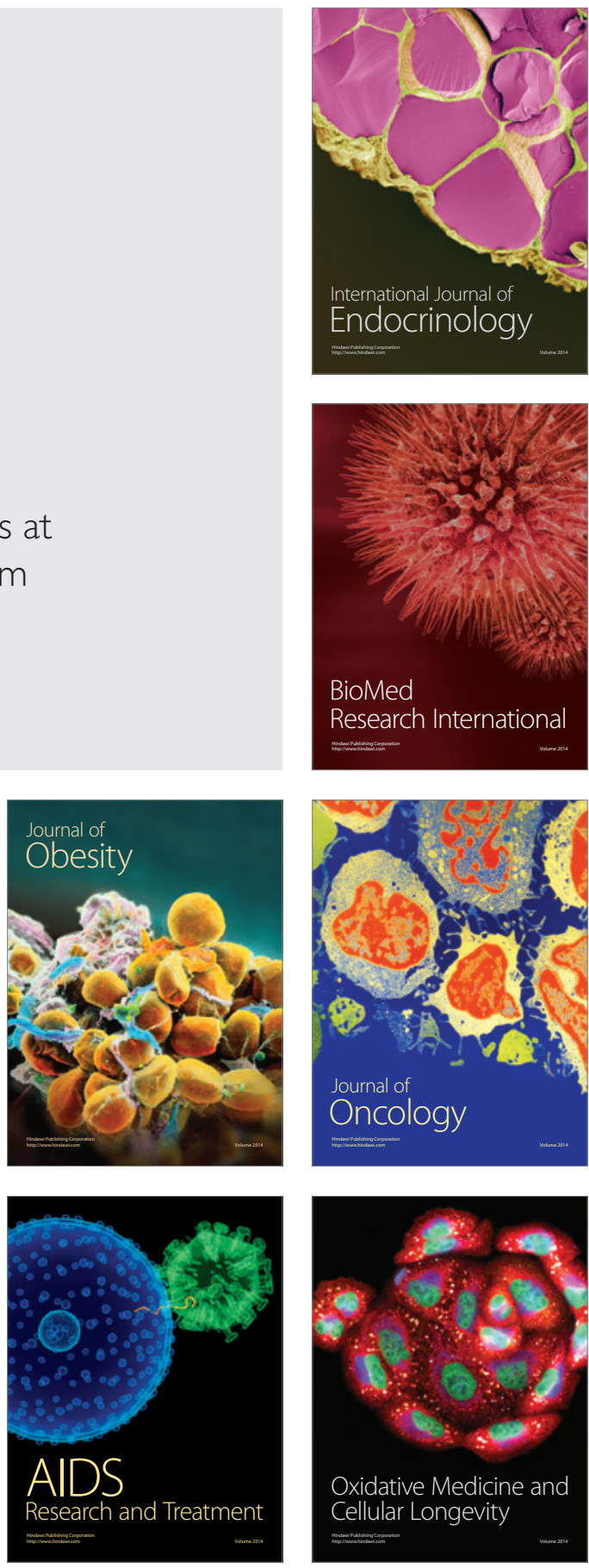